\title{
Inelastic deformation and destruction of fiber-laminated polymer composites in stress concentration zones
}

\author{
Elena M. Strungar, Valery E. Wildemann \\ Perm National Research Polytechnic University, Russia \\ cem.spaskova@mail.ru,bttp://orcid.org/0000-0002-2246-8638 \\ wildemann@pstu.ru, bttp: / /orcid.org/0000-0002-6240-4022
}

\begin{abstract}
The article is devoted to the experimental study of the laws of inelastic deformation of structural polymer composites in the presence of macroinhomogeneous fields. The work uses a three-dimensional optical system and a method of digital image correlation, thermoscanning equipment. The relationship between the selected parameters of the correlation analysis and the scale level of the deformation processes is shown. Experimental data were obtained confirming the presence of a large-scale effect of strength in a certain range of structural parameter values, data on the features of the deformation of composites with various reinforcement schemes, as well as in the presence of technological defects. Recommendations on the use of a video system for calibration and sensitivity assessment of integrated fiberoptic sensors are presented.
\end{abstract}

KEYWORDs. Experimental mechanics; The method of digital image correlation; Stress concentrator; Fiber-laminated polymer composites; The scale effect of strength

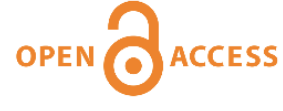

Citation: Strungar, E. M., Wildemann, V. E., Inelastic deformation and destruction of fiber-laminated polymer composites in stress concentration zones, Frattura ed Integrità Strutturale, 53 (2020) 406-416.

Received: 19.05 .2020

Accepted: 24.05 .2020 Published: 01.07.2020

Copyright: (C) 2020 This is an open access article under the terms of the CC-BY 4.0, which permits unrestricted use, distribution, and reproduction in any medium, provided the original author and source are credited.

\section{INTRODUCTION}

$\mathrm{D}$ ue to their high specific physical and mechanical properties fiber-laminated polymer composite materials are widely used in critical aviation structures. Experimental studies that provide the assessment of evolution of displacement and strain fields in stress concentration zones as well as the specific features of composites behavior in these zones, are necessary for improvement of inelastic behavior models, the development of calculation models and designing the critical structure elements [1-9]. Alongside with various geometry concentrators, in particular, the holes, the structure defects that occur in the process of manufacture or operation may become prospective concentrators [10-14].

The method of digital image correlation (DIC) is one of promising experimental displacement and strain fields analysis methods. The development of a new method for solution of deformable solid mechanics tasks calls for complex studies of efficacy of the use of experimental mechanics "instrument" with reference to the analysis of mechanical behavior of solids of various geometry and structures during implementation of complex external impact modes [15-21]. This work 
aimed at obtaining new experimental data about the regularities of evolution of displacement and strain fields in the zones of composite elements stress concentration at inelastic behavior by means of digital image correlation method appears relevant.

Despite the significant achievements of experimental composite mechanics, the issues that need extra studies include complex theoretical and experimental study of damage accumulation process regularities, defects development, structural and macro-damage of structural polymer composite materials operating under the conditions of non-homogeneous strain fields in the parts with various geometry concentrators. It is noted that the composite materials structure complexity results in the necessity of consideration the defects at various levels, and finding the damage development stages [22-24]. The objective of this work is the experimental study of regularities of inelastic deformation, the processes of damage accumulation and structure polymer composite materials damage under the condition of non-homogeneous strain fields.

\section{METHODOLOGY AND METHODS OF RESEARCH}

his work was carried out in Perm National Research Polytechnic University using Unique Scientific Equipment «Complex of testing and diagnostic equipment for studying properties of structural and functional materials under complex thermomechanical loading».

Registration and analysis of evolution of non-homogeneous strain fields and the temperatures on the surface of structurally non-homogeneous material provided the joint use of in-situ optical methods of experimental mechanics: the highly efficient method of digital images correlation (DIC) on the basis of three-dimensional digital optical system Vic-3D (Correlated Solutions) and infra-red tomography method FLIR SC7700M with thermal imaging system with MCT (Mercury-Cadmium Telluride) cooled detector. The quantitative comparison of the images in DIC method is provided by means of computation of image conformity factor according to one the criteria and the search for its extremum. This work uses the criteria of normed sum of squared differences with zero mean [15]. In the process of data processing, we establish the surface points displacement fields, and the transition to deformation is performed by means of finite strain tensor in the sense of Lagrange [15]. The analysis of composite material damage due to macro-fissure development, the study of developmental prototype fracture surfaces was performed with the use of stereomicroscope Carl Zeiss SteREO Discoverjy.V12.

The study of inelastic deformation processes, the accumulation of damages and development of defects in composite objects depending of stress conditions and modes provided the performance of mechanical tests at quasi-static loading at multipurpose electromechanical test system Instron $5882(100 \mathrm{KN})$, Instron $5989(600 \mathrm{KN})$ as well as at cyclic loading with various cycle parameters at servohydraulic two-axis (tensile-and-compression/torsion) test system Instron 8850 (100 $\kappa \mathrm{N} / 1000 \mathrm{Nm})[8]$.

\section{METHODICAL SPECIFICS OF THE USE OF DIGITAL IMAGES CORRELATION AND DIGITAL OPTICAL SYSTEMS METHOD AT COMPOSITE MATERIALS TESTING}

$\mathrm{T}$ he paper considers the methodical issues of conducting the experiment with the use of digital optical system for 3D analysis of displacement and strain fields. The method DIC suggests the selection of correlation analysis parameters, in particular, the subarea size $\mathrm{X}$ and the step value $\Delta \mathrm{X}$. During the correlation processing of digital images the displacement vectors computation is performed not at each individual image point (pixel), but through the study area discretization into small local study areas or sub-areas. The step is another parameter to be set in the algorithm of building the displacement vector fields, its size determines the procedure of search and identification of image sections. The step value sets the distance between the points analyzed in the process of mathematical processing in pixels [15].

In view of the fact that composite materials possess significant structural non-homogeneity, which is not considered in the method DIC, the authors performed a number of calculations of deformation fields on the surface of dimensionally laminated carbon composite for one frame at various values of subarea in the interval of $\mathrm{X}=9 \div 89$ pixels and at the fixed step value $\Delta X=5$. The authors have built a diagram of dependence of the subarea size impact on the results of correlation ratio calculation Fig. 1).

The paper takes into account the recommendation of literature sources [15], that the subarea size is acceptable if correlation ration does not exceed $\sigma \leq 0.01$ [15]. The selected subarea size $49 \times 49$ has sufficient uniqueness of pixels 
distribution for the possibility of conclusive identification of local areas from the image. At smaller parameter size X, the unaffordable correlation ratio values are observed.

Based on the study conducted it is observed that the selection of parameters should be performed in consideration of the size of structural non-homogeneity of the material; in view of this fact, the scale level of deformation registration is selected. To assess the structural specificity of the material, to study the processes of origin and development of defect structures and damage, the analysis of behavior in the stress concentration zones it is necessary to establish the step value consistent with the structural non-homogeneity size [21].
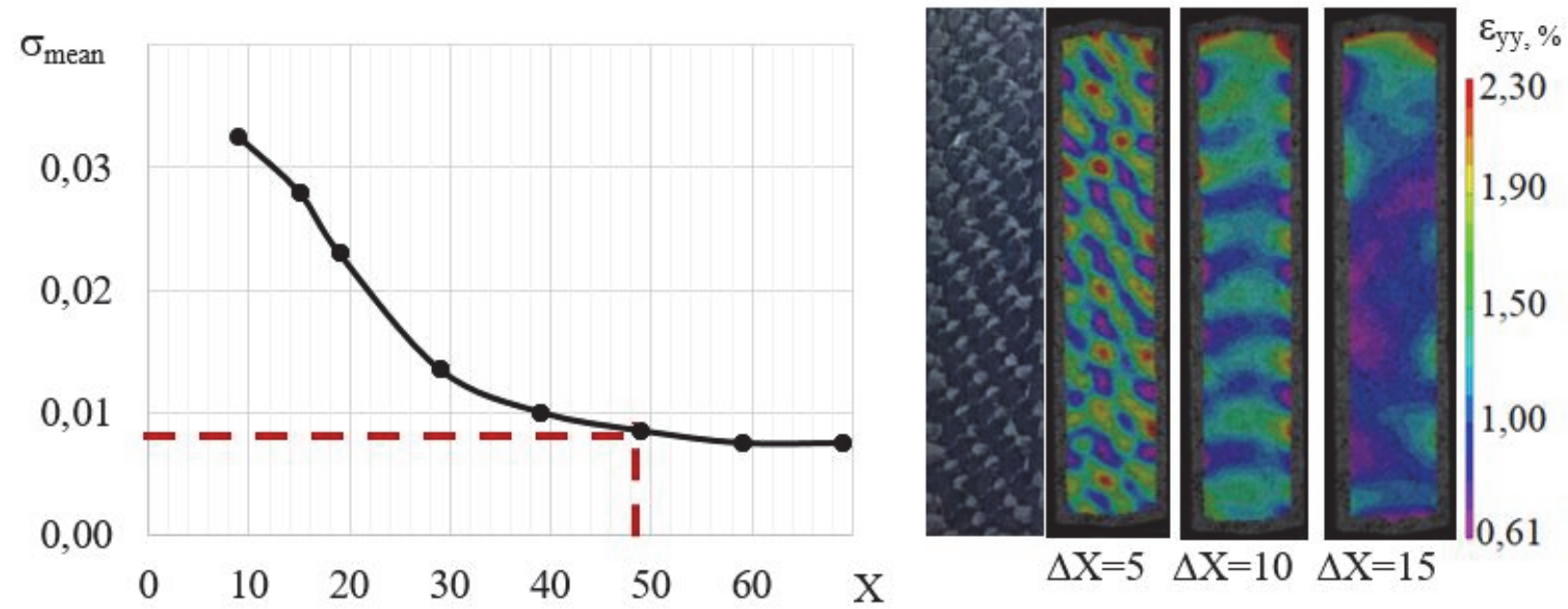

Figure 1: The effect of subarea size on the results of calculation of correlation ratio; non-homogeneous longitudinal strain fields at a fixed size of subarea and various step values.

Due to the fact that the video-system precision is not a fixed value but depends on various mathematical parameters, the authors conducted a study to confirm the precision of the measurements obtained using a three-dimensional optical system, a series of tests for uniaxial stretching of a fiberglass flat sample was carried out using amounted extensometer Instron 2620-601 and additional Vic-3D software module of "virtual extensometer" (Fig. 2). The characteristics of the extensometer Instron 2620-601 are as follows: the maximal possible deviation from the measured value is $0.15 \%$. The measuring base of the mounted extensometer is $50 \mathrm{~mm}$.

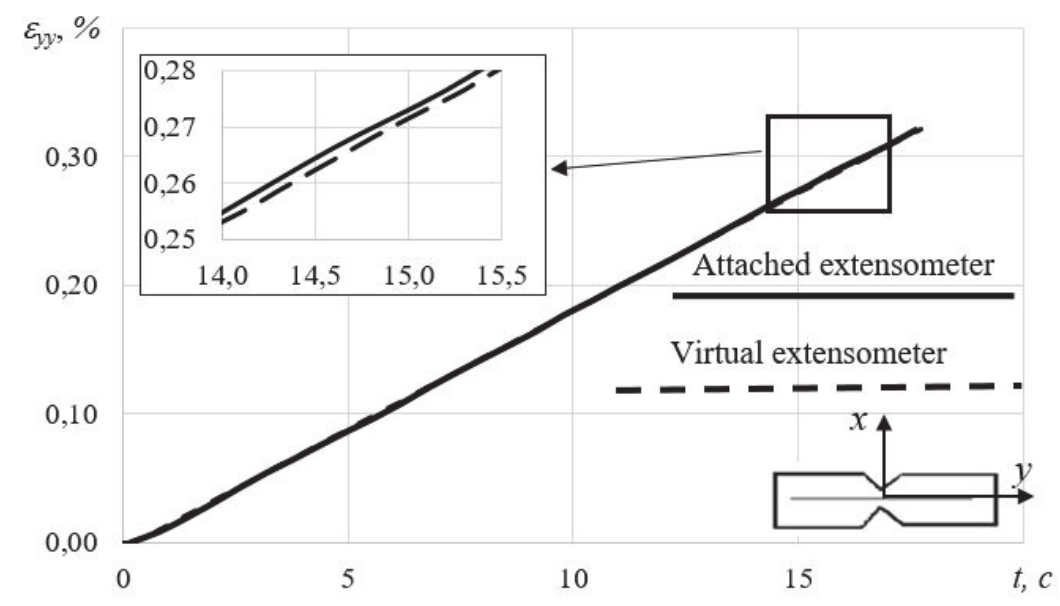

Figure 2: Longitudinal strain-time diagram.

According to the test results, it was concluded that the use of a digital optical system makes it possible to determine the deformation values on a fixed basis, with the accuracy consistent with the data of the mounted longitudinal strain gauge 


\section{THE ANALYSIS OF THE MECHANISMS OF INELASTIC DEFORMATION AND THE COMPOSITES DESTRUCTION IN THE CONCENTRATORS ZONES IN CONSIDERATION OF STRUCTURAL PARAMETERS}

$\mathrm{I}$ $\mathrm{n}$ the process of creation of structures, it is often necessary to make the holes of various size in their elements due to the process considerations. The following part of the paper presents the results of experimental studies of mechanical behavior of a fiber-laminated composite material in the vicinity of stress concentrators. The authors tested the fiberglass samples for uniaxial tension with different values of through hole diameter. Fig. 3 presents the comparative analysis of the descending sections of the diagram for diameters $\mathrm{d} 1-\mathrm{d} 5$. With the increase of diameter, the descending sections extend, the degree of implementation of the supercritical stage rises. The angle (slope modulus) of the curves changes as well.
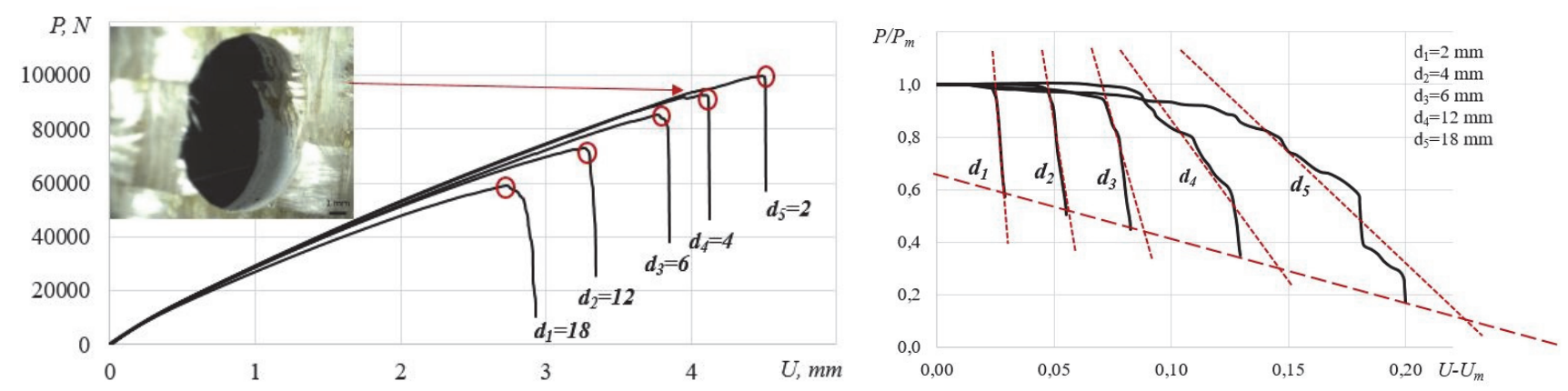

Figure 3: Load diagram for samples with different hole diameters during uniaxial tensile tests; the comparative analysis of the descending sections of the diagram.

The analysis of the composite material damage due to macro-fissure development was carried out using a stereo microscope Carl Zeiss SteREO Discoverjy.V12 in the upper layers. In large deformation areas, the fiber breakage is observed around the holes on both sides, the evidence of this fact is shown in the image of the sample surface (Fig. 4).

Due to the results obtained, the geometrically similar samples are of special interest; the program of assessment of the effect of structural parameters of the composite samples with the tension concentrator included mechanical tests for uniaxial tension of three groups of strip samples with different hole diameters 3, 6 и $9 \mathrm{~mm}$.

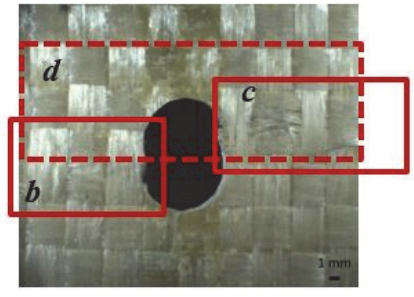

$a$

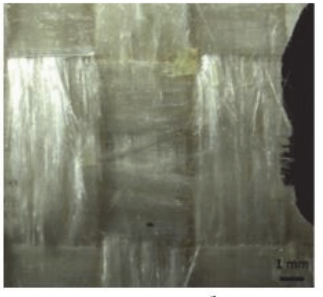

$b$

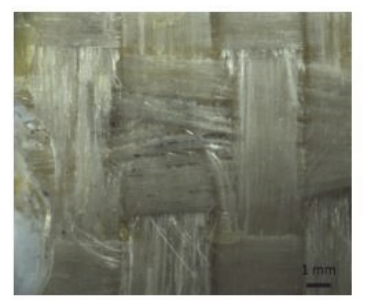

c

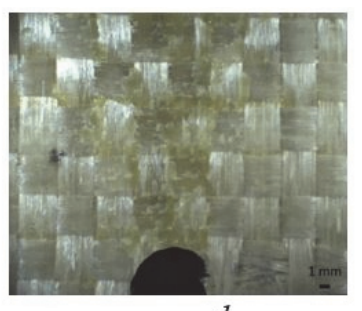

$d$

Figure 4: The images of fiberglass structure after the destruction of the sample on the upper layer.

When selecting the width and length of the working part of the sample, the similarity of geometric dimensions was observed: the hole diameter $\mathrm{d}(\mathrm{mm})$, the width of the working part $\mathrm{h}=6 \mathrm{~d}(\mathrm{~mm})$, the length of the working part $l=14 \mathrm{~d}$ $(\mathrm{mm})$, the speed of movement $1 \cdot 0.01(\mathrm{~mm} / \mathrm{min})$ of the movable grabber provided similar strain rate in the working areas of all samples $\left(1.7 \cdot 10^{-4} \mathrm{~s}^{-1}\right)$.

The average stress value was determined by the formula $\sigma=\mathrm{P} /(5 \mathrm{dh})$. Fig. 5 shows the characteristic deformation diagrams. The destruction occurred due to the formation of the fiber breakage band, besides, the formation of extensive delamination regions was recorded. In the course of study the authors found a large-scale effect, the bearing capacity decreased with the increase of the hole diameter. The detected scale effect can be attributed to the fact that, depending on the hole size, various volumes of a structurally non-homogeneous medium are involved in the work. 


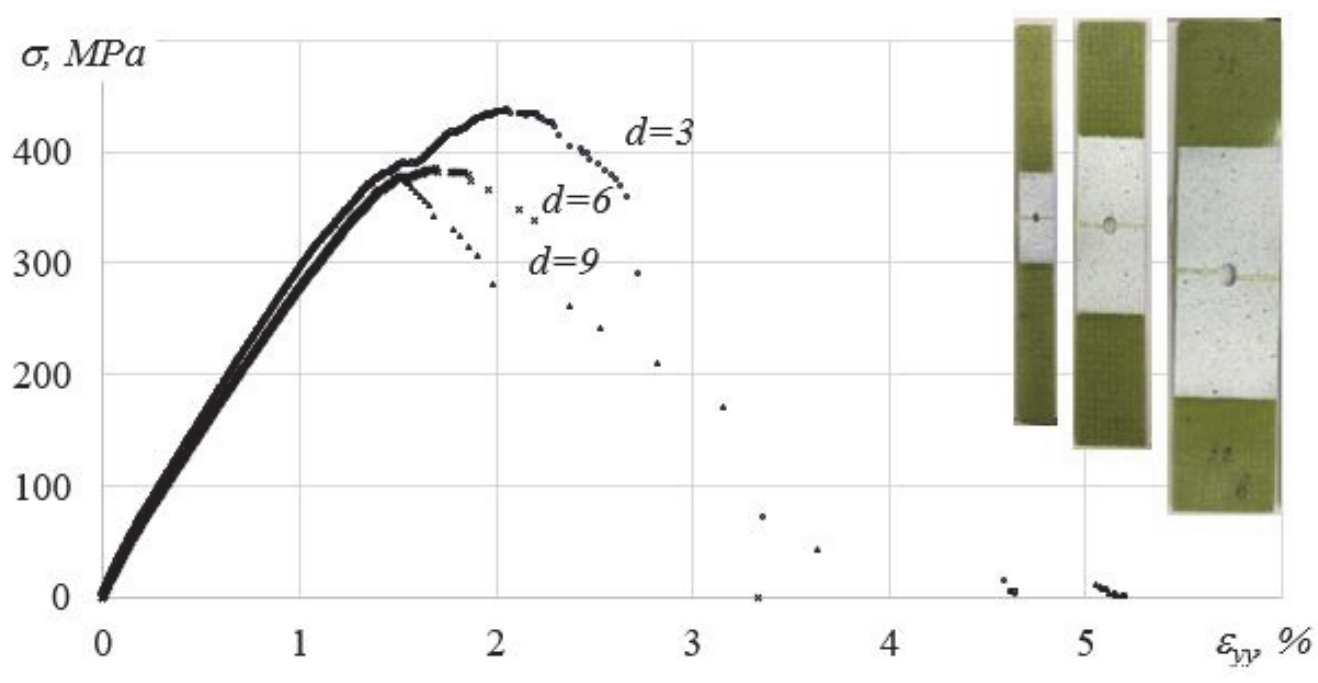

Figure 5: The diagram of samples deformation at uniaxial tensile test.

The work deals with structurally non-homogeneous solids, and a change in the size of the sample and the hole affects the bearing capacity, it can be assumed that it is attributed to the material structure. In this regard, a diagram of dependence of the limiting value of the average stress on non-homogeneity parameter was obtained for samples with different hole diameters (Fig. 6).

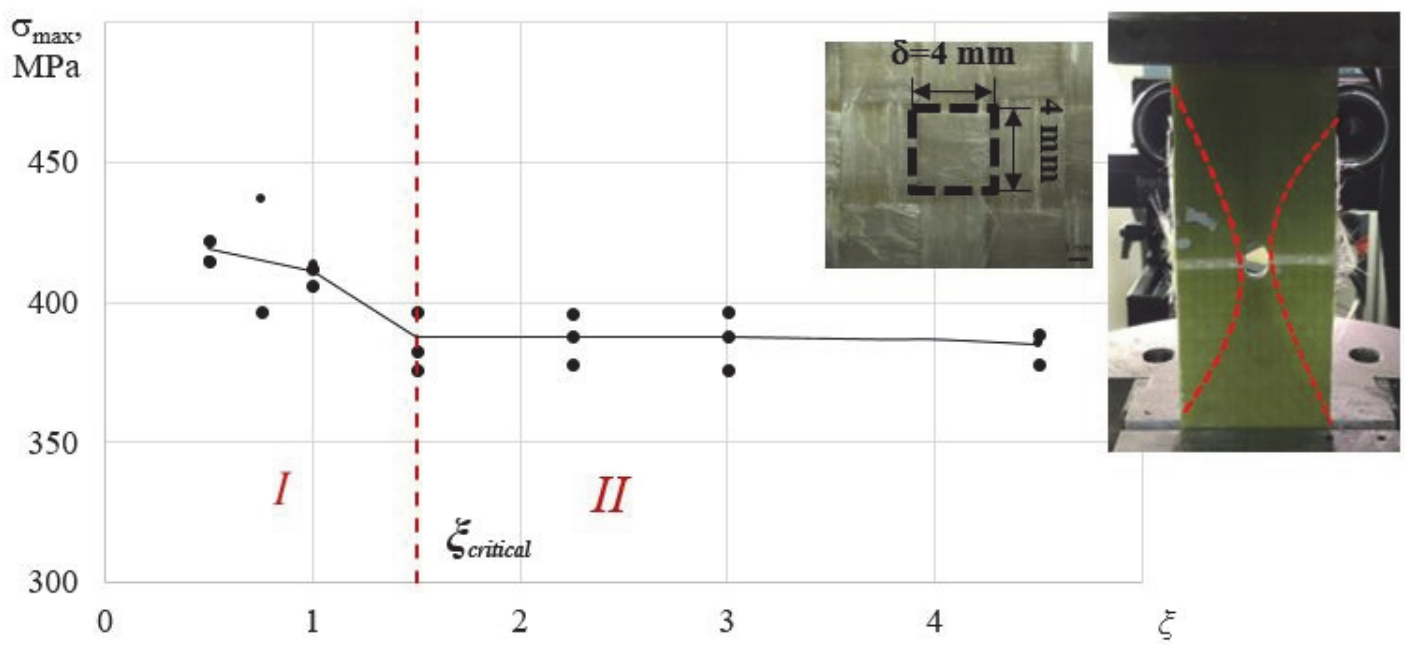

Figure 6: The diagram of dependence of the limiting value of the average stress on non-homogeneity parameter and the image of destroyed sample with fiber breakage and matrix delamination areas.

Non-homogeneity parameter was introduced for quantitative analysis, it depends on the hole diameter and the size of the structural element and is calculated by the formula $\xi=\mathrm{d} / \delta$. The size of the structural element for this material was $\delta=4$ $\mathrm{mm}$ (weave width).

The dependence of the specific strength characteristics on the specified parameter is shown in Fig. 6. It is seen, that a critical value of non-homogeneity parameter can be introduced $\xi_{\text {critical }}=1,5$. Conditionally, the diagram in Fig. 6 can be divided into two sections: section I $\left(\xi \leq \xi_{\text {critical }}\right)$ and section II $\left(\xi<\xi_{\text {critical }}\right.$. When the values of the structural nonhomogeneity parameter are less than the critical value, the limiting values of the average stress decreased (Section I); the obtained data indicate the presence of a scale effect.

When the structural non-homogeneity parameter is greater than the critical value for the specific material, there is practically no change in the limiting values of the average voltage (section II), while there is no scale effect.

The use of the video-system makes it possible to use the deformation fields in the vicinity of the concentrator. The analysis of longitudinal strain $\left(\varepsilon_{\mathrm{yy}}\right)$ distribution on the surface, along the line $\mathrm{L}$ drawn from the hole to the edge of the plate 
is performed for composite samples. Strain diagram are built at particular level of strain $(\sigma)$ 150, 250, $350 \mathrm{MPa}$ for a sample with the hole diameter $\mathrm{d}=3,6,9 \mathrm{~mm}$ (Fig. 7).
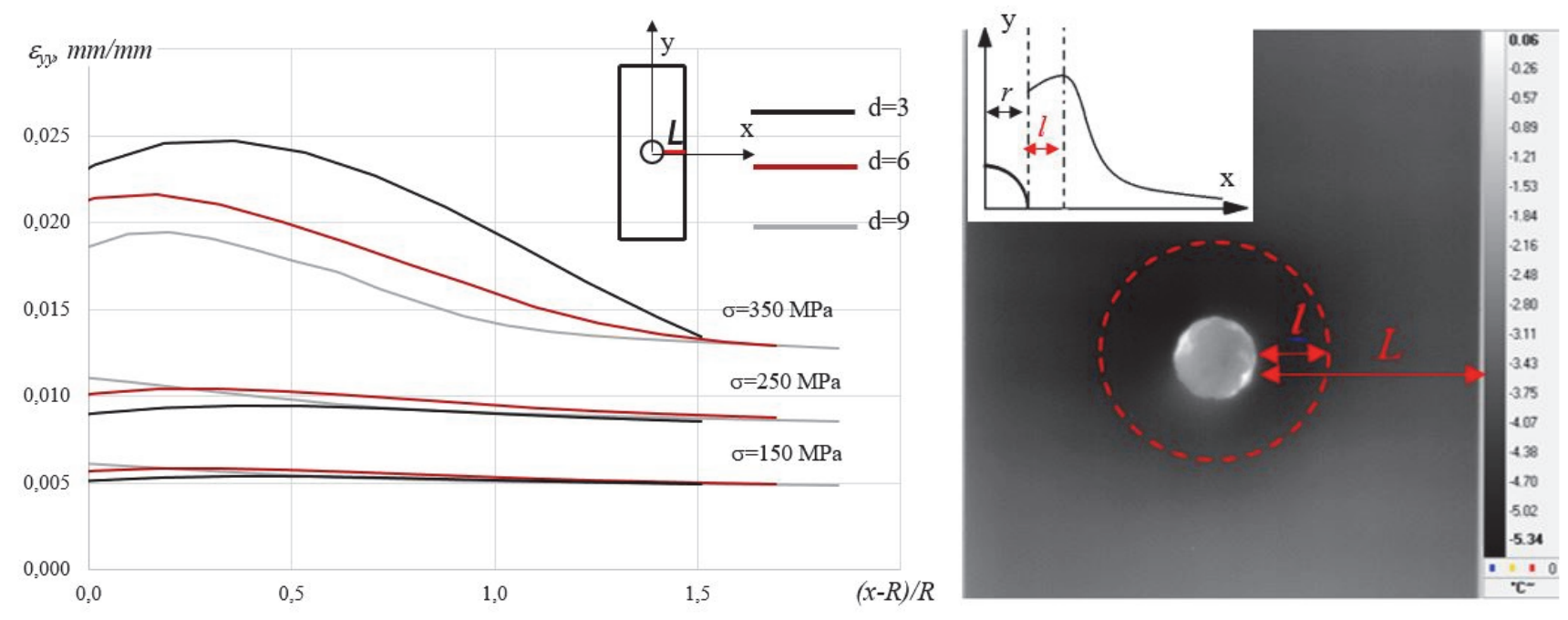

Figure 7: Longitudinal strain diagrams $\mathrm{d}=3,6,9 \mathrm{~mm}$ on the sample surface with diameter size at various strain level; a thermogram of unloaded sample before the test $\mathrm{d}=6 \mathrm{~mm}$.

It has been found that in the process of inelastic deformation the maximal values of longitudinal strain at extension of the sample displace from the boundary of the hole. It is possible to assume that such peculiarity of mechanical conduct is related to the presence of defects in the vicinity of the hole. To confirm this fact, thermal scanning is performed after short-term heating. The corresponding results are provided in Fig. 7. A local heating is found in the area of the opening which indirectly confirms the supposition of a defect area.

Structural and deformational properties determining the composite's behavior at shear, belong to important characteristics of any composite. The study of these properties of materials is associated with specific methodic difficulties [25,26]. The paper considers Iosipescu method ASTM D5379. There are various international standards for these mechanical tests. The paper shows that these standards need adjustment for a number of structures. The authors suggested recommendations for obtaining and mathematical processing of experimental data using contactless optical video-system. To determine shear deformations, ASTM D5379 recommends to use resistance strain gauges with $1.5 \mathrm{~mm}$ basis situated at the angle of $\pm 45^{\circ}$ to the loading area in the working area of the sample (between V-shaped cutout), but the video-system software makes it possible to simulate the resistance strain gauges using supplementary virtual instruments. Based on the tests, deformation fields were built for each of the 10 samples in their working areas in consideration of the structural properties. Fig. 8 shows the analyzed options of averaging the deformations in the working area of spatially reinforced samples using such video-system elements as "virtual extensometer T" and "rectangular area R" [28].

In the course of deformation fields study it was found that shear deformations distribution is of non-homogeneous nature, depending on non-homogeneity areas location, the data values may vary by shear module by more than 1.6 times, by nominal shear strength - by 1.4 times, by strength limit - by 1.1 times [28]. It should be pointed out that experimental studies were conducted at 8 spatially reinforced structures, but only two structures have such peculiarity

For determination of shear deformations for spatially reinforced structures according to ASTM D5379, a video-system has advantages over resistance strain gauges and is more preferable to use because it provides the full pattern of shear deformations distributions on sample surface [28].

\section{THE ANALYSIS OF DEFORMATION AND DAMAGE ACCUMULATION PROCESSES IN COMPOSITE OBJECTS WITH STRESS CONCENTRATORS OF PROCESS AND MAINTENANCE ORIGIN}

7 he previously provided results illustrate deformation fields in consideration of sizes of the sample concentrators and structure elements. Defects, fissures, healing areas may also be the possible concentrators. The next part of the work is devoted to it. The process of manufacture of the sample with imbedded process defects of "delamination" type is based on the use of fluoroplastic film laid between the layers. 
For experimental study of deformation processes and accumulation of damages in carbon fiber composite samples with internal defects under complex stressed conditions the authors implemented mechanical tests at proportional extension/compression with torsion at $\mathrm{k}=0.028(\mathrm{k}=\mathrm{u} / \varphi)$. To assess the internal defect development the tests were conducted with three unloadings and repeated loadings. In the event of internal defect development in the process of loading the change of deformation fields pattern is recorded (Fig. 9) [13,14].
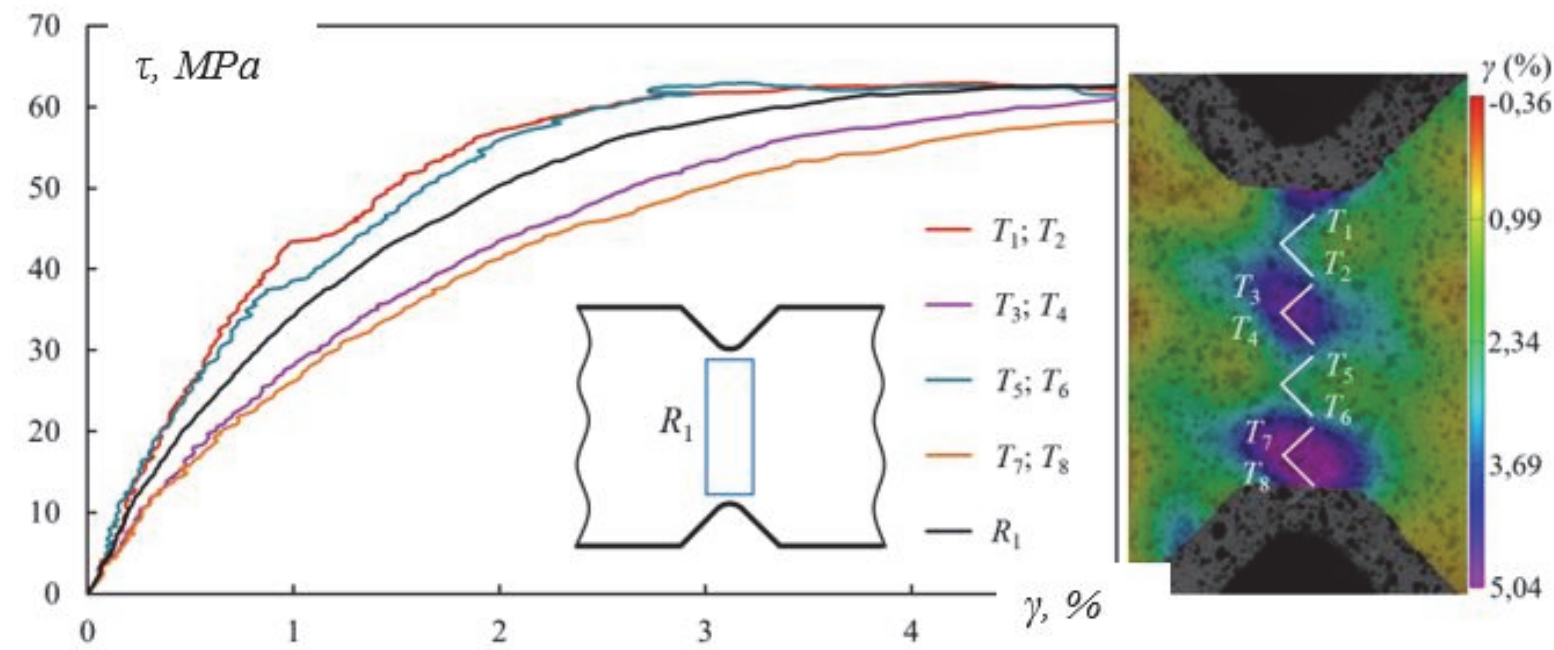

Figure 8: The diagrams of sample deformation using the instruments "virtual extensometer T" and "rectangular area R" to determine shear deformations.

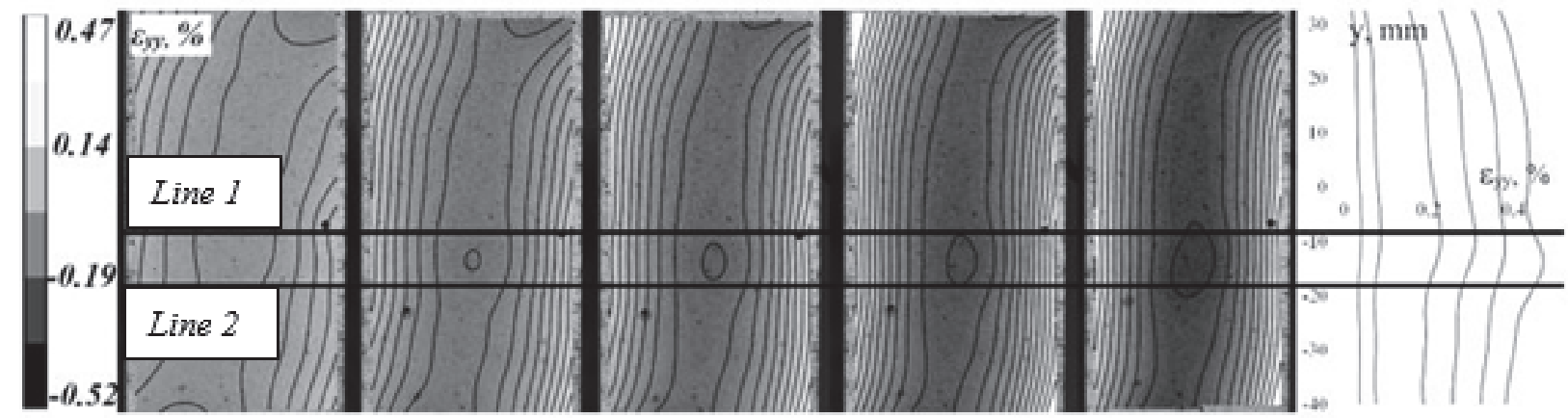

Figure 9: Non-homogeneous longitudinal strain fields on the sample surface with the defect size $10 \times 10 \mathrm{~mm}$.

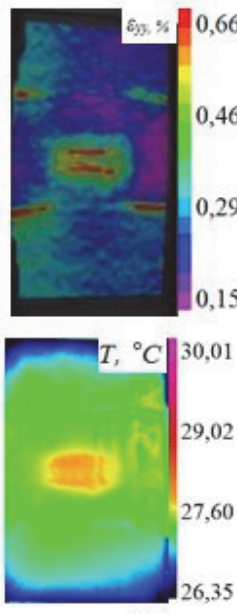

$\mathrm{n}=50$
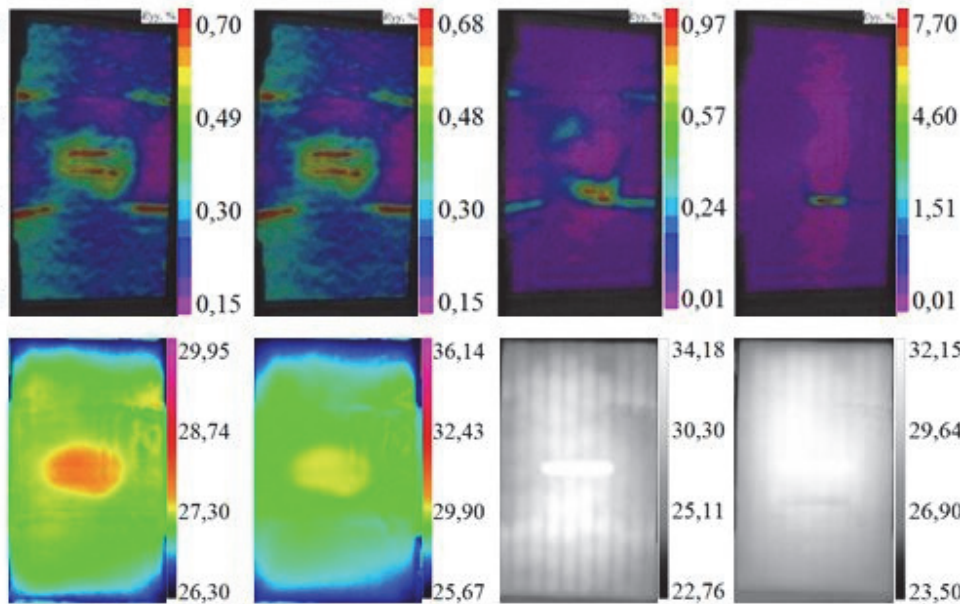

$\mathrm{n}=80$

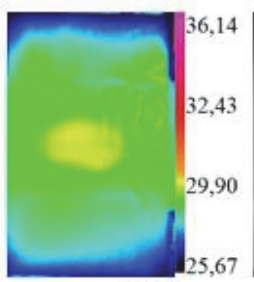

$\mathrm{n}=100$

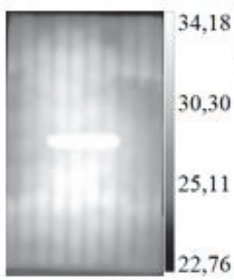

$\mathrm{n}=160$

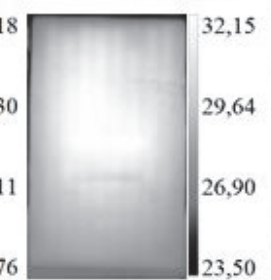

$\mathrm{n}=180$
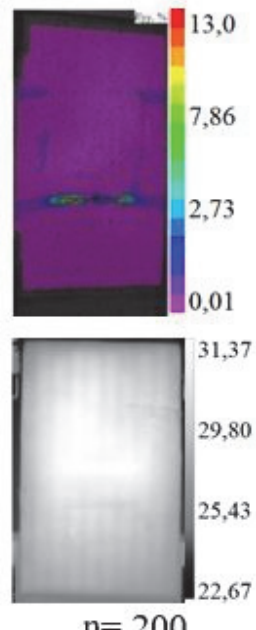

Figure 10: Longitudinal strain fields evolution and the corresponding thermograms depending on the number of performed loading cycles. 
Special attention is paid to analysis of deformation fields pattern evolution for assessment of development of the healed reach-through breakdown defects and formation of macro-damage conditions in three-layer composite fiberglass laminate panels. The authors suggested a method of study of the defect effect on residual strength of the elements of composite structures based on the joint use of the systems of deformation fields and temperatures registration. They assessed the effect of cyclic tests on behavior of defect-containing composites with the following parameters: asymmetry coefficient $\mathrm{R}=-0.25$; cycle amplitude $\mathrm{Na}=25 \mathrm{kN}$; sinus wave shape; frequency $-0.25 \mathrm{~Hz}$; the number of cycles $\mathrm{n}=200$. The minimal values at loading constituted $-10 \mathrm{kN}$, the maximal ones $-40 \mathrm{kN}$ (Fig. 10).

It is shown that the bearing capacity of a sample with a defect applied is $30 \%$ lower than that of a defectless sample. Cyclic loadings under the above-discussed modes resulted in another strength reduction by $10 \%$ [12].

\section{THE USE OF DIGITAL IMAGE CORRELATION METHOD FOR SOLUTION OF FIBER OPTIC TECHNOLOGY TASKS}

A mong the present-day and promising diagnostic instruments, the monitoring systems based on the introduction of fiber optic deformation sensors (FODS) which are effective both under production conditions and during operation of various purposes products and objects, are of special interest. Introducing FODS into the composite structure, it is necessary to solve a number of technical and scientific problems. One of the trends of the use of DIC method may be the use of this instrument to solve the problems of fiber optic technologies [14,27]. The final part of the paper shows that the use of video systems for three-dimensional analysis of the displacement and deformation fields makes it possible to develop recommendations for location and calibration of built-in fiber optic deformation sensors FODS (taking into account the calibration coefficient provides the increase of precision of deformations recorded by FODS by $25 \%$ ), and assess the sensitivity to loading modes [27].

Besides, the paper studied the organization of the equilibrium fissure growth mode. This study provides the results of experiments on registration of deformations under cyclic loading, and the development of recommendations on registration the damages based on the results of measuring the deformations during cyclic loading. In this case, we provided not an instant development of the damage area, but its development with a rate that allows us to speak about significant effect of the number of cycles on destruction.

To analyze the deformation fields and determine the locations of the optical sensors to record the origin and development of damage in the polymer composite material, we implemented a multi-stage cyclic loading according to Fig. 11 diagram. The transition from one stage to another was carried out with the decrease in the value of the load amplitude Pa by more than $5 \%$. A sample with a lateral cutout was used as the study object, it served as a stress concentrator, in the vicinity of which the damages first occur under loading. The longitudinal deformation fields and the corresponding images obtained using a microscope are shown in Fig. 12[14].

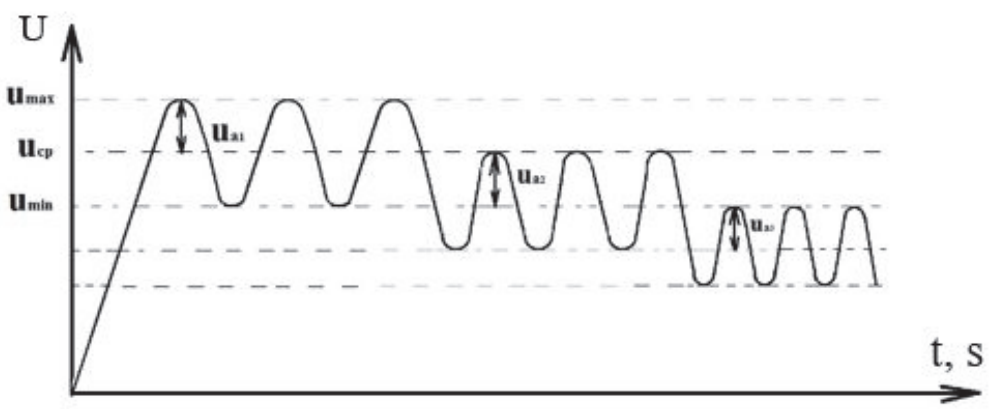

Figure 11: Staged strain mode.

Similarly, this technique was applied to carbon fiber composite samples; a loading-time diagram with the marked points corresponding to longitudinal strain fields is shown in Fig. 13. The criterion for transition from one stage to another was the change in the value of the loading amplitude $\mathrm{Pa}$ by $3,10,50 \%$.

In the course of a staged cyclic loading necessary for recording the origin and development of damages in the polymer composite material, a more equilibrium fissure growth is observed for fiberglass samples, than for carbon fiber composite samples. The presented technique is necessary for determining the locations of optical sensors during registration of origin and development of damages in a polymer composite material 

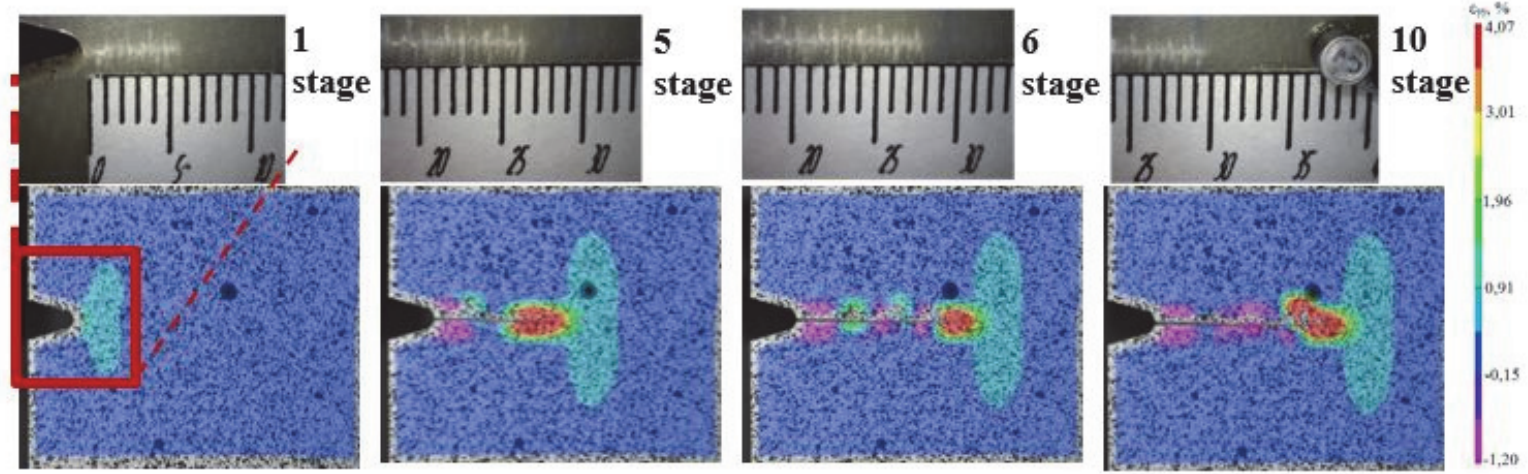

Figure 12: Evolution of longitudinal strain fields during a fissure growth for a fiberglass samples.
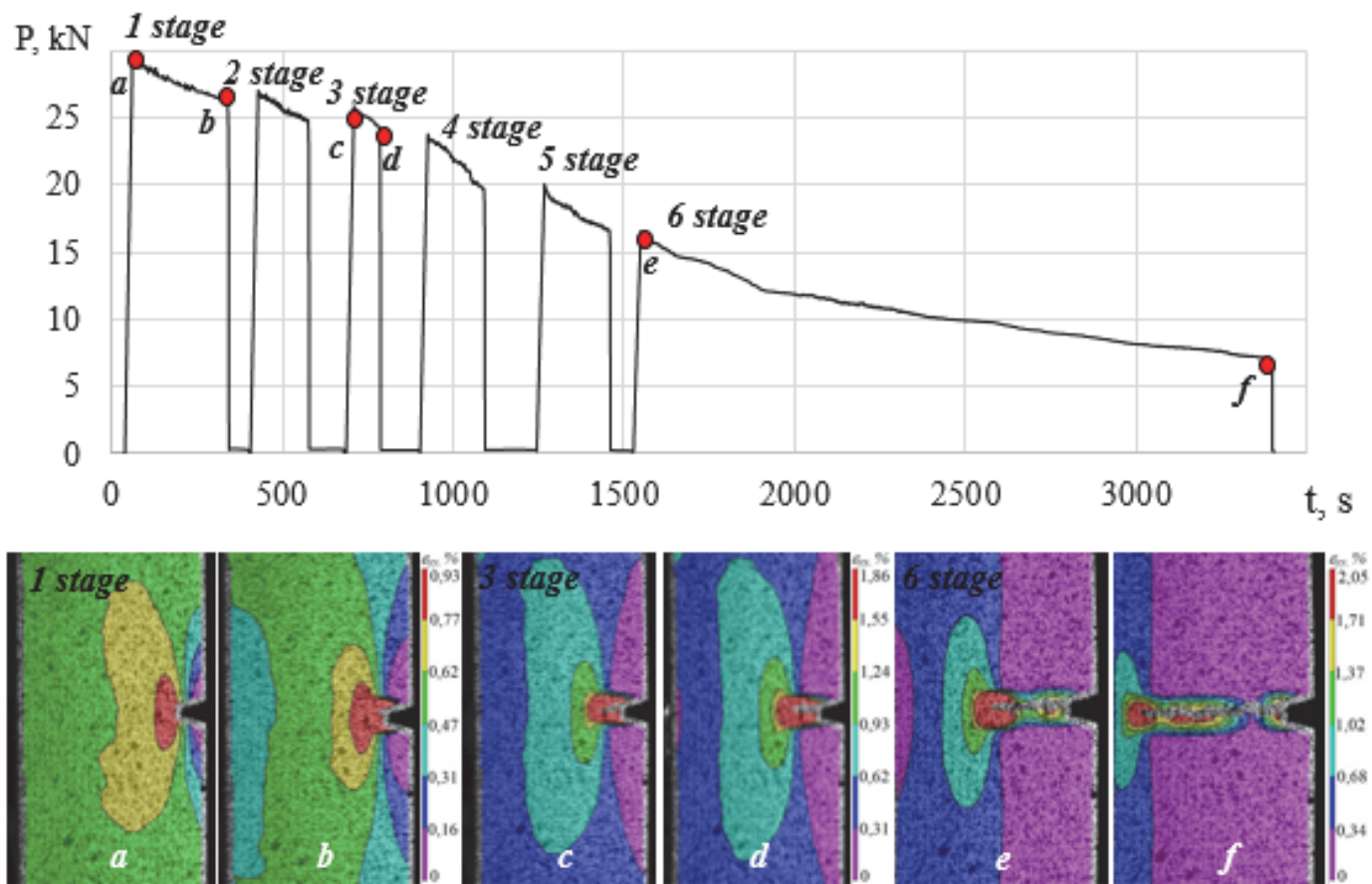

Figure 13: Evolution of longitudinal strain fields during a fissure growth for a fiberglass samples.

\section{CONCLUSIONS}

7 herefore, the paper analyzes numerical algorithms for processing the experimental data using the digital image correlation method. The authors suggested recommendations on selection of calculation parameters for analysis of non-homogeneous displacement and strain fields in composite products taking into account the structural nonhomogeneity of materials. They have shown the correlation between the selected parameters of the correlation analysis and the scaled level of the consideration of strain processes. Since there is a correlation between the selected processing parameters and the characteristic size of the strain averaging region, the selection of building the vector fields predetermines the possibility of identifying the features of strain localization at various scales.

The authors conducted experimental studies of the mechanical behavior of fiber-laminated composite materials in the vicinity of stress concentrators under quasistatic loading. The results of assessment of the effect of the hole size in relation to the characteristic size of the composite material structure on the processes of inelastic deformation and breakage have been obtained. The data confirming the presence of a scale effect of strength in a certain range of values of material structural heterogeneity parameter have been obtained. 
Recommendations on obtaining and mathematical processing of experimental data for determining the mechanical characteristics of composites under shear, using a contactless optical video system have been suggested.

To analyze the regularities of mechanical behavior of materials in the areas of process and operational imperfections, the processes of strain and accumulation of damage in sandwich composite objects with pre-embedded defects have been experimentally studied. The authors analyzed the evolution of strain field patterns to assess the development of defects in composite samples. They suggested a technique for studying the effect of defects on the residual strength of composite structural elements based on the joint use of strain fields and temperatures recording systems.

Experimental data on assessment of the effect of defects on the residual strength of structurally similar composite structural elements have been obtained. The load-bearing capacity of coarse-grained panels with the damages under cyclic and quasi-cyclic impacts has been assessed.

The paper provides a complex study of usability of digital images correlation method for solution of fiber optic technology tasks. It is shown that the use of video-systems for three-dimensional analysis of the displacement and strain fields makes it possible to develop recommendations for location and calibration of built-in fiber optic sensors, and assess the sensitivity to loading modes.

\section{ACKNOWLEDGEMENTS}

$\mathrm{E}$ xperimental studies were carried out using the large-scale research facilities «Complex of testing and diagnostic equipment for studying properties of structural and functional materials under complex thermomechanical loading» PNRPU modernized with funds by the Ministry of Science and Higher Education of the Russian Federation, Unique project identifier RFMEFI61920X0017.

\section{REFERENCES}

[1] Staniera, D., Radhakrishnana, A., Genta, I., Shankhachur Roy, S., Hamertona, I., Potlurib, P., Scarpa, F., Shaffer, M., Ivanov, D. S. (2019). Matrix-graded and fibre-steered composites to tackle stress concentrations, Composite Structures, 207, pp. 72-80. DOI: 10.1016/j.compstruct.2018.09.019.

[2] Fedulov, B. N., Fedorenko, A. N., Kantor, M. M., Lomakin, E. V. (2018). Failure analysis of laminated composites based on degradation parameters, Meccanica, 53(1-2), pp. 359-372. DOI: 10.1007/s11012-017-0735-9.

[3] Hadjem-Hamouche, Z., Derrien, K., Héripré, E., Chevalier, J. P. (2018). In-situ experimental and numerical studies of the damage evolution and fracture in a Fe-TiB2 composite, Materials Science and Engineering: A, 724, pp. 594-605. DOI: doi.org/10.1016/j.msea.2018.03.108

[4] Junshan, H., Kaifu, Z., Hui, C., Ping, L., Peng, Z., Danlong, S. (2017) Stress analysis and damage evolution in individual plies of notched composite laminates subjected to in-plane loads, Chinese Journal of Aeronautics, 30(1), pp. 447-460. DOI: 10.1016/j.msea.2018.03.108.

[5] Krzyzak, D., Robak, G., Lagoda, T. (2015). Determining fatigue life of bent and tensioned elements with a notch, with use of fictitious radius, Fatigue \& fracture of engineering materials \& structures, 38(6), pp. 693-699. DOI: $10.1111 /$ ffe. 12276.

[6] Lagattu, F., Lafarie-Frenot, M.C., Lam, T.Q., Brillaud, J. (2005). Experimental characterisation of overstress accommodation in notched CFRP composite laminates, Composite Structures, 67(3), pp. 347-357.

DOI: 10.1016/j.compstruct.2004.01.016.

[7] Tretyakova, T.V., Vildeman, V.E. (2017). Influence the loading conditions and the stress concentrators on the spatialtime inhomogeneity due to the yield delay and the jerky flow: study by using the digital image correlation and the infrared analysis, Frattura ed integrità strutturale, 11(42), pp. 303-314. DOI: 10.3221/IGF-ESIS.42.32.

[8] Wildemann, V.E. at all. (2011). The mechanics of materials. Methods and means of experimental research. Perm: Publishers Inc. PNRPU, 165 p.

[9] Wildemann, V.E. (2012). Experimental studies of the properties of materials under complex thermomechanical effects. M.: FIZMATLIT, 204 p.

[10] Emery, T.R., Dulieu-Barton, J.M. (2010). Thermoelastic Stress Analysis of damage mechanisms in composite materials, Composites Part A: Applied Science and Manufacturing, 41, pp. 1729-1742.

DOI: $10.1016 /$ j.compositesa.2009.08.015. 
[11] Tashkinov, M. A. (2017). Modelling of fracture processes in laminate composite plates with embedded delamination, 11 (39), pp. 248-262. DOI: 10.3221/IGF-ESIS.39.23.

[12] Lobanov, D.S., Wildemann, V.E., Spaskova, E. M., Chikhachev, A.I. (2015). Experimental investigation of the defects influence on the composites sandwich panels strength with use digital image correlation and infrared thermography methods. PNRPU Mechanics Bulletin, No. 4, pp. 159-170. DOI: 10.15593/perm.mech/2015.4.10.

[13] Wildemann, V. V., Tretyakova, T. V., Strungar, E. M., Tretyakov, M. P. (2018). Deformation and failure of carbon fiber composite specimens with embedded defects during tension-torsion test, Frattura ed Integrità Strutturale, 12(46), pp. 295-305. DOI: 10.3221/IGF-ESIS.46.27.

[14] Lobanov, D.S., Strungar, E.M., Zubova, E.M., Wildemann, V.E. (2019). Studying the Development of a Technological Defect in Complex Stressed Construction CFRP Using Digital Image Correlation and Acoustic Emission Methods, Russian Journal of Nondestructive Testing, 55, pp. 631-638. DOI: $10.1134 /$ S1061830919090031.

[15] Sutton, M.A., Orteu, J.-J., Schreier, H. (2009). Image Correlation for Shape, Motion and Deformation Measurements. - University of South Carolina, Columbia, SC, USA, 364 p.

[16] Huh, Y.-H., Kim, J., Hong, S., Park, J. H. (2015). Measurement of hole damage characteristics in the glass fibre reinforced plastic composite using digital image correlation technique, Material wissenschaft und Werkstofftech, 46(4-5), pp. 446-453. DOI: 10.1002/mawe.201500420.

[17] Khechai, A., Tati, A., Guerira, B., Guettal,a A., Mohite, P.M. (2018). Strength degradation and stress analysis of composite plates with circular, square and rectangular notches using digital image correlation, Composite Structures, 185, pp. 699-715. DOI: 10.1016/j.compstruct.2017.11.060.

[18] Mehdikhani, M., Aravand, V., Sabuncuoglu, B., Callens, M. G., Lomov, S.V., Gorbatikh, L. (2016). Full-field strain measurements at the micro-scale in fiber-reinforced composites using digital image correlation, Composite Structures 140, pp. 192-201. DOI: 10.1016/j.compstruct.2015.12.020.

[19] Tretyakova, T. V., Spaskova, E.M. (2013). Experimental study of limit stress-strain state quasi-brittle material using correlation techniques digital images. PNRPU Mechanics Bulletin, 2, pp. 186-198.

[20] Wildemann, V.E., Spaskova, E.V., Shilova, A.I. (2016). Research of the damage and failure processes of composite materials based on acoustic emission monitoring and method of digital image correlation problems of deformation and fracture in materials and structures, Solid State Phenomena, 243, pp. 163-170.

DOI: 10.4028/www.scientific.net/SSP.243.163.

[21] Tretyakova, T.V., Dushko, A.N., Strungar, E.M., Zubova, E.M., Lobanov, D.S. (2019). Comprehensive analysis of mechanical behavior and fracture processes of specimens of three-dimensional reinforced carbon fiber in tensile tests, PNRPU Mechanics Bulletin, 1, pp. 173-183. DOI: 10.15593/perm.mech/2019.1.15.

[22] Camanho, P.P., Maimı, P., Dávila, C.G. (2007). Prediction of size effects in notched laminates using continuum damage mechanics, Compos Sci Technol, 67, pp. 2715-2727.

DOI: 10.1016/j.compscitech.2007.02.005.

[23] Frantziskonis, G., Deymier, P. (2006). Surface effects at the nanoscale significantly reduce the effects of stress concentrators, Probabilistic engineering mechanics. 21(3), pp. 277-286.

DOI: 10.1016/j.probengmech.2005.10.004.

[24] Green, B.G., Wisnom, M.R., Hallet, S.R. (2007). An experimental investigation into the tensile strength scaling of notched composites, Composites-Part A, 38, pp. 867-878.

DOI: 10.1016/j.compositesa.2006.07.008.

[25] Babushkin, A.V., Babushkina, A.V., Strungar, E. M., Staroverov, O. A., Lobanov, D. S., Temerova, M.S., Feklistova E.V. (2019). Phenomenological characteristics structural features research obtained at fibrous plastics standard tests, Procedia Structural Integrity, 17, pp. 658-665. DOI: 10.1016/j.prostr.2019.08.088.

[26] Strungar, E. M., Feklistova, E.V., Babushkin, A.V., Lobanov, D. S. (2019). Experimental studies of 3D woven composites interweaving types effect on the mechanical properties of a polymer composite material, Procedia Structural Integrity, 17, pp. 965-970. DOI: 10.1016/j.prostr.2019.08.128.

[27] Anoshkin, A. N., Voronkov, A. A., Kosheleva, N. A., Matveenko, V. P., Serovaev, G. S., Spaskova, E. M., Shardakov, I. N., Shipunov, G. S. (2016). Measurement of inhomogeneous strain fields by fiber optic sensors embedded in a polymer composite material, Mechanics of Solids, 51(5), pp. 542-549. DOI: $10.3103 /$ S0025654416050058.

[28] Strungar, E.M., Yankin, A.S., Zubova, E.M., Babushkin, A. V., Dushko, A. N. (2020). Experimental study of shear properties of 3D woven composite using digital image correlation and acoustic emission. Acta Mech. Sin, 36(2).

DOI: $10.1007 / \mathrm{s} 10409-019-00921-7$. 